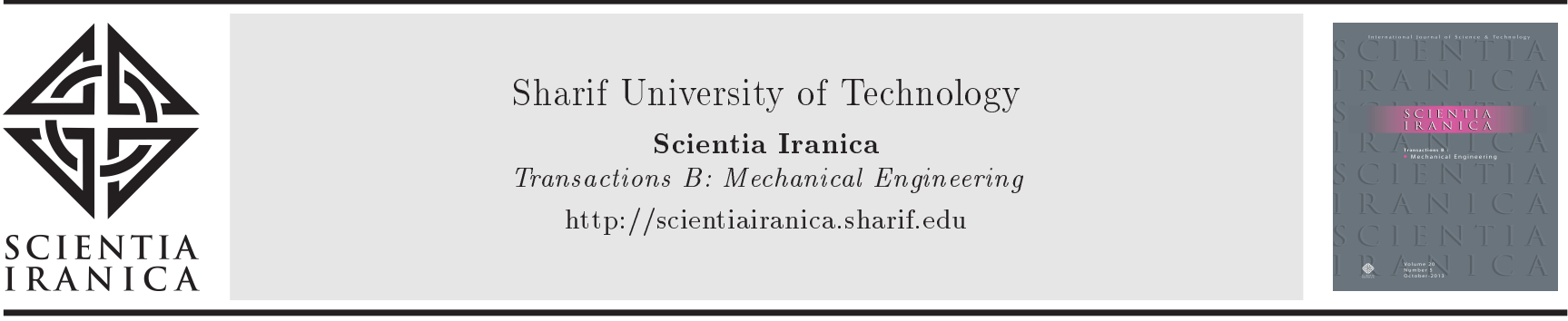

\title{
Numerical and experimental analysis of the air distribution system in a data center building to improve the thermal performance
}

\author{
M. Narimani and A. Abbassi* \\ Department of Mechanical Engineering, Amirkabir University of Technology, Tehran, Iran.
}

Received 21 July 2020; received in revised form 17 January 2021; accepted 17 May 2021

\section{KEYWORDS}

Data centers;

Numerical simulation;

Thermal management;

Raised floor;

Aisle

\begin{abstract}
The purpose of the management of air distribution systems is to solve the problems of the cooling of data centers through minimizing the hot air recirculation and cold air bypass. In this paper, experimental and numerical analyses are conducted for the Amirkabir University of Technology (AUT) data center. The data center performance indices of experimental and numerical solutions have been compared. According to temperature contours at a height of $1 \mathrm{~m}$ from the raised floor, recirculation of hot air to the cold aisle has occurred. To ensure the accuracy of the results, the thermal management of the data center, the cold aisle enclosure that reduces the supply air temperature to 18 degrees, and the hot aisle that returns hot air from the ventilated ceiling to the Computer Room Air Conditioning (CRAC) unit were studied. As the total airflow supplied by the CRAC units in the cold aisle enclosure and hot aisle models was reduced, the problem that the airflow of the super-micro servers is about $50 \%$ higher than the airflow defined in the basic model has been resolved. The load on the cooling systems decreased from $13.2 \mathrm{~kW}$ to $7.8 \mathrm{~kW}$ in the hot aisle, the result is a hot aisle and a more appropriate configuration for the data center.
\end{abstract}

(C) 2021 Sharif University of Technology. All rights reserved.

\section{Introduction}

A data center is a facility that includes computer systems, such as storage and communications systems, backup systems, or additional equipment that can be used as a backup in the event of major systems failures and also includes environmental controllers, such as air conditioning and fire systems [1]. One of the most common equipment in data centers is the rack. The rack is

*. Corresponding author. Tel.: +982122727087 E-mail addresses: Mahdi.narimani@aut.ac.ir ( $M$. Narimani); abbassi@aut.ac.ir (A. Abbassi)

doi: $10.24200 /$ sci. 2021.56116 .4554 a metal enclosure used to maintain and protect various network equipment such as cable, switches, servers, telecommunication equipment, uninterruptible power supplies, etc. Since heat dissipation on the rack server is constantly increasing, designing a well-ventilated system in the data center to prevent the equipment from being damaged by the heat is important [2]. Cooling systems consume $37 \%$ of the total energy needed in data centers, which constitute a high percentage of energy consumption [3]. Deployment of air distribution systems that reduce energy consumption by improving PUE metrics [4] and preventing hotspots for servers' reliable operation [5] is essential. Ventilation through the raised floor of Under-Floor Air Distribution (UFAD) is a newly developed displacement ventilation system 
that has an impressive effect on the improvement of thermal conditions [6]. The most important purpose of data center cooling systems is to maintain acceptable operating temperatures. Therefore, the solution to ensure the proper operation is that the cool air must be distributed properly and satisfies the needs of each area in the data center. One of the solutions for better cooling efficiency is to prevent the mixing of return air with supply air at the inlet and outlet of each rack. Adding the number of cooling units and increasing their power is not a good way to manage airflow in data centers [7].

Many researchers have studied different configurations of data centers in the context of thermal conditions. Among them, Nada and Elfeky [8] investigated various configurations of cold aisles containment and comparisons between different states. These states were: free open cold aisle, semi-enclosed cold aisles where the aisles are enclosed from the sides, and full enclosed cold aisles where the aisles are enclosed from sides and top. This study showed that the percentage of enhancement in data center performance due to using cold aisle dramatically increases with increasing the power density. Yuan et al. [9] applied Flexible Baffles (FBs) for different arrangements of them in the air inlet of racks to improve the airflow distribution in a data center. They concluded that the optimum thermal environment occurs when the racks are equipped with $20 \mathrm{~cm} \mathrm{FBs}$ at an angle of $75^{\circ}$ in the vertical direction of the rack. Nada et al. [10] by studying thermal performance for different configurations of CRAC (Computer Room Air Conditioning) units and aisles separation showed that the effect of the location of racks and air-conditioners on the thermal indices was significant. Chao et al. [11] examined the effect of aisle enclosure on the cooling efficiency of data centers with a low cooling load. Cho and Kim [12] evaluated the air distribution management system in high-density data centers using 6SigmaDCX software. To improve RHI (Return Heat Index) and SHI (Supply Heat Index), they proposed an underfloor air distribution system with return flow through the ceiling plenum duct from the hot aisle to CRACs units. Also, to improve RTI (Return Temperature Index) and RCI (Rack Cooling Index), they proposed a cold aisle partitioning system with a height of $0.6 \mathrm{~m}$. Huang et al. [13] developed a numerical simulation of a data center with three different types of air distribution: An under-floor air supplying system, a row-level cooling system, and rack cooling performance. They concluded that the rack level airflow pattern shows the best performance in data center cooling. Yanmei [14] developed a numerical simulation of a data center in Singapore with 6 SigmaDCX software and concluded that by cold aisle enclosure with return hot airflow from the ceiling to CRACs units, by-pass airflow is reduced and the energy consumption of the air conditioner fans decreases by 20-25\%. Cho and Kim [12] proposed a vertical aisle partition system in high-density data centers to increase cooling efficiency associated with heat exhaustion from IT servers output. Yuan et al. [15] introduced and analyzed an in-rack cold aisle system. The results showed that the optimal thermal distribution is achieved in a case with $0.6 \mathrm{~m} \times 0.6 \mathrm{~m}$ in-rack air inlet and partition plane.

Some investigations performed numerical simulations for the effect of the flow parameters and the conditions of air cooling systems on the thermal performance of data centers. In a study by Ling et al. [16], the design of the floors plenum with tiles and the dependence of the pressure loss coefficient across perforated tiles to the geometrical factors and flow parameters were investigated. Karki and Patankar [17] have examined the fluid mechanics in the plenum of the raised floor using a one-dimensional computational model. Within the one-dimensional framework, various variables affecting the plenum-flow-field and hence the lateral-flow-distribution can be combined into two dimensionless parameters:

(a) The pressure variation parameter;

(b) The frictional resistance parameter.

The results show that an increase in the value of the pressure variation parameter increases the nonuniformity. The frictional resistance parameter, on the other hand, controls the pattern of the lateral flow distribution. When the frictional resistance is small, the lateral flow rates are lowest near the inlet. Nada and Said [18] investigated the effect of plenum depth on the performance of data centers for different opening ratios of the tiles and racks power densities. They concluded that the perforated tile opening ratios of 25 to 30 percent and plenum depth of $60 \mathrm{~cm}$ can be considered as appropriate values for data centers [18]. Schmidt and Iyengar [19] also examined the airflow conditions for high-density data centers. The result of this study was that supplying airflow from the floor with a return of air from the ceiling plenum is the best model for airflow conditions. Cho et al. [20] tried to reduce energy consumption in high-density data centers by improving the efficiency of cooling and distribution of air. Priyadumkol and Kittichaikarn [21] showed that the increase in velocity and airflow rate from the underfloor tiles was not a good solution to eliminate overheating points above the racks at a height of 2 meter and they proposed in-row cooling systems for these cases. Chu et al. [22] studied the effects of air supply flow rate on the cooling performance of a data center by Computer Room Air Handler (CRAH), intake flow rate of rack cooling fans, air supply grilles, and the non-uniform heat load distribution [22]. 
In this study, the synergy of the geometrical factors and flow parameters regarding the thermal performance of data centers has been investigated. The goal of air-distribution systems management is to solve the problems in the data centers cooling systems through minimizing re-recirculation of hot air, minimizing cold air bypass, and eliminating excessive cold points. Recirculation flow and bypass flow (Figure 1) reduce the efficiency of the cooling system [23]. The use of temperature indices helps to understand the efficiency and performance of air distribution. Sharma et al. [24] presented two dimensionless parameters of SHI and RHI for assessing the temperature of the environment of data centers. Herrlin [25] studied the effect of rack cooling and introduced RCI, which indicates the cooling rate of the equipment. This metric also can be used to design new data centers. Herrlin [26] conducted a study on RTI, which is a measure of the baseline of by-pass air or recirculation air in the data centers. Both by-pass air and recirculation air have a bad effect on the overall energy and thermal efficiency of the space and create hot spots [26]. Most of the investigations cited in the literature performed numerical simulations for the imaginary data center model. While reviewing these CFD (Computational Fluid Dynamics) studies, it seems that the thermal management of data centers to overcome the server inhomogeneous temperature distribution by varying server flow rates, heat load, and location of the servers at different slots of racks were not investigated. This study aims to examine the effect of the reduction of the flow rates and supply air temperatures of the cooling systems on the thermal performance of the Amirkabir University of Technology (AUT) data center which is considered for configuring the hot aisle and cold aisle. Previously, this issue is not investigated for CFD modeling of data centers. In this research, the distribution of air and temperature at the AUT high-speed processing center has been studied using numerical simulation with 6Sigmadcx software. Then, the results of numerical simulation are investigated and validated according to the experimental results measured in the data center. In Section 1, the results of temperature indices from experimental measurements are compared with numerical solution

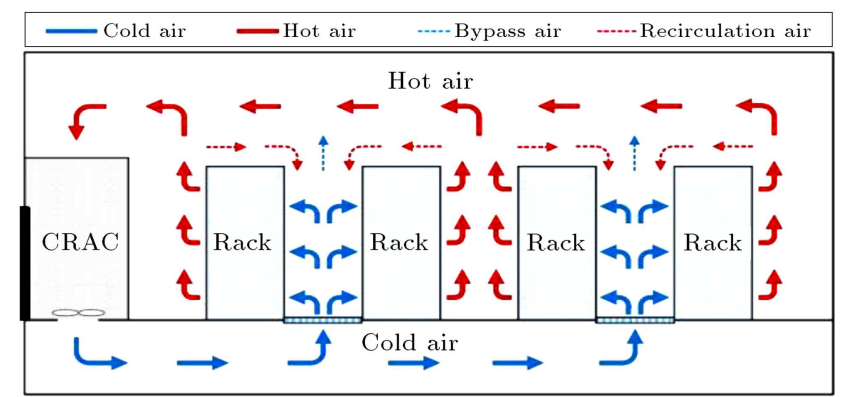

Figure 1. Re-circulation and by-pass airflow. results. According to the results, re-circulation of hot air and cold air by-pass negatively affects the cooling process of the servers and causes non-uniformity and elevation of air temperatures at the server intakes. In Section 2, to solve these problems and improve the thermal performance of the air distribution system and also to provide proper control on actual servers, the data center once has been simulated with a cold aisle enclosure and again with a hot aisle enclosure with the return flow from the ceiling plenum; the results of cases have been compared with the results of the main model of the data center.

\section{Methodology}

\subsection{Data center description}

AUT data center server room with dimensions of $12.4 \mathrm{~m} \times 8.7 \mathrm{~m} \times 2.5 \mathrm{~m}$ has been considered as the physical model (Figure 2(a)). The height of the plenum of the raised floor is $0.64 \mathrm{~m}$. A total of 12 tiles with dimensions of $0.6 \mathrm{~m} \times 0.6 \mathrm{~m}$ and an opening ratio of $50 \%$ is installed in the cold aisle for cooling the racks. This center includes 19 racks with dimensions of $1.97 \mathrm{~m} \times 0.75 \mathrm{~m} \times 1 \mathrm{~m}$, arranged in two rows with a spacing of $1.8 \mathrm{~m}$ between the two rows (cold aisle

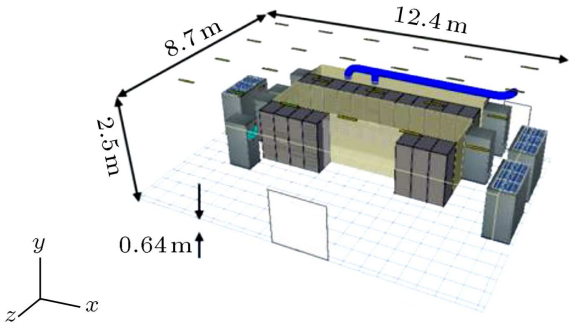

(a)

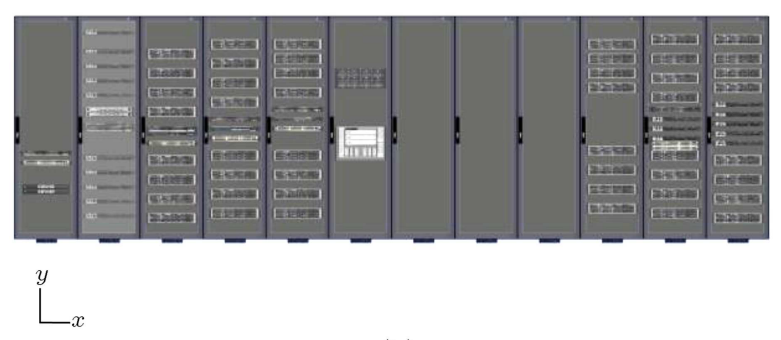

(b)
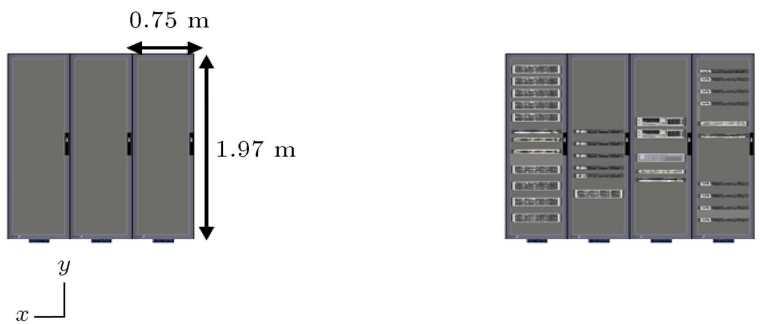

(c)

Figure 2. (a) 3D view of IT server room. (b) Cabinets of row 1. (c) Cabinets of row 2. 


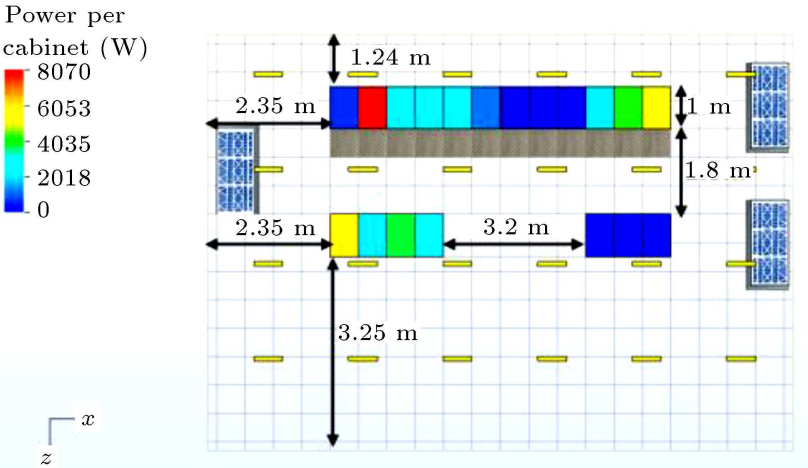

Figure 3. Power of per cabinet.

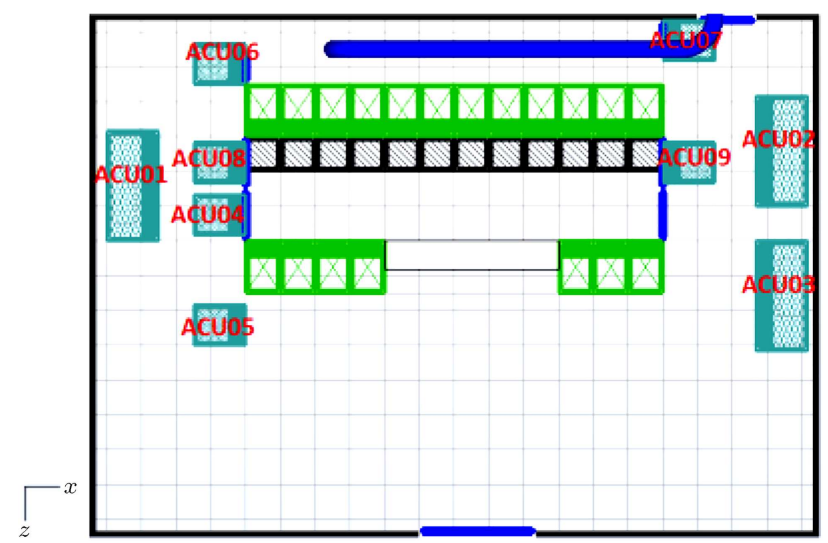

Figure 4. Numbering of Computer Room Air Conditioning (CRAC) units, ACU: Air Conditioning Unit.

pitch). The first row has 12 racks, where the distance of this row from the sidewall (longitudinal) and the transverse wall respectively is $1.24 \mathrm{~m}$ and $2.35 \mathrm{~m}$. The racks of this row and their servers and switchers in different slots of each cabinet are shown in Figure 2(b). The second row has 7 racks, where the distance of this row from the sidewall (longitudinal) and the transverse wall, respectively, is $3.25 \mathrm{~m}$ and $2.35 \mathrm{~m}$. The racks of this row with the servers and switchers of them in different slots of each cabinet have been shown in Figure 2(c). The total heat load of the server room was $65 \mathrm{~kW}$, of which $42.2 \mathrm{~kW}$ was from IT equipment, $13.2 \mathrm{~kW}$ was from cooling systems, and $9.6 \mathrm{~kW}$ was from the data center lighting. The heat load per cabinet is shown in Figure 3. Both of hot aisle and cold aisle are enclosed and a circular vent with $60 \mathrm{~cm}$ diameter has been installed on the east wall of the room to exhaust hot air at a flow rate of $1.25 \frac{\mathrm{m}^{3}}{\mathrm{~s}}$ from the hot aisle enclosure with a circular duct of $60 \mathrm{~cm}$ diameter at the overhead of racks 3 and 5 (Figure 2(a)). There was a $3.2 \mathrm{~m}$ gap in the middle of the second row as the cold aisle enclosure door. The total capacity of the cooling systems and air conditioner units was $195 \mathrm{~kW}$. The specifications and boundary conditions for CRAC units according to Figure 4 are given in Table 1 . In Figure 4 arrangement of CRAC units is shown.
Table 1. Specification of Computer Room Air Conditioning (CRAC) units.

\begin{tabular}{cccc}
\hline $\begin{array}{c}\text { No of } \\
\text { CRAC } \\
\text { unit }\end{array}$ & $\begin{array}{c}\text { Power } \\
(\mathbf{k W})\end{array}$ & $\begin{array}{c}\text { Flow rate } \\
\left(\frac{\mathbf{m}^{3}}{\mathbf{s}}\right)\end{array}$ & $\begin{array}{c}\text { The temperature } \\
\text { of discharge air } \\
\left({ }^{\circ} \mathbf{C}\right)\end{array}$ \\
\hline ACU01 & 40 & 3.6 & 22 \\
ACU02 & 40 & 3.6 & 22.4 \\
ACU03 & 40 & 3.6 & 22.7 \\
ACU04 & 12.5 & 1.2 & 22 \\
ACU05 & 12.5 & 1.2 & 25 \\
ACU06 & 12.5 & 1.2 & 29 \\
ACU07 & 12.5 & 1.2 & 31 \\
ACU08 & 12.5 & 1.2 & 22 \\
ACU09 & 12.5 & 1.2 & 24 \\
\hline
\end{tabular}

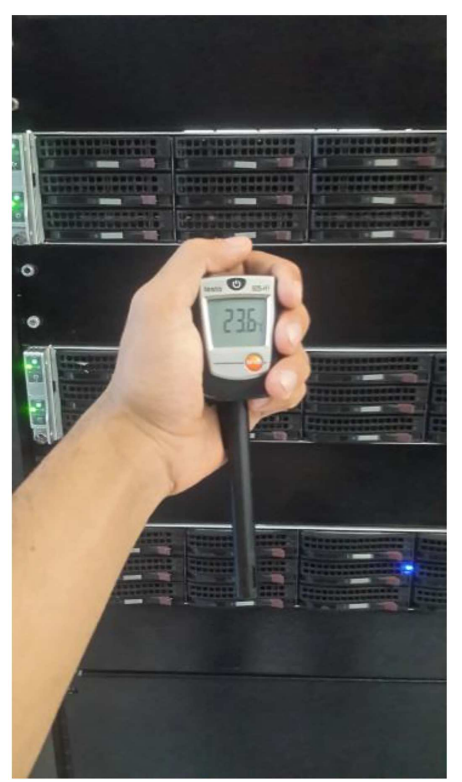

Figure 5. Testo temperature measurement device.

\subsection{Experimental setup}

In this study, experiments were carried out in July and August of 2019. The built-up test facility was equipped with Testo 605-H1 digital thermometer (Figure 5) to measure different parameters needed for later analysis such as intake and outlet temperature of racks. For an empirical simulation of the data center, the temperature at 39 points of the data center, i.e., the intake temperature of each rack at $0.2,1$, and $1.8 \mathrm{~m}$ aboveraised floor is measured. Note that these measurements are measured at a distance of $5 \mathrm{~cm}$ from the input and output of each rack server. Note that because some racks were empty, no temperature measurement is taken. The aim of the experiments was to obtain temperature distribution in the data center for calculating the data center performance indices. The quantities measured directly in the experiment include maximum 
Table 2. Data center-CFD model boundary conditions.

\begin{tabular}{lccc}
\hline Boundary conditions & Symbol & Equation & Value \\
\hline Tile flow rate & $Q_{t}$ & $Q_{t}=U_{0} A_{\text {tile }}$ & $18 \frac{\mathrm{m}^{3}}{\mathrm{~s}}$ \\
Inlet air temperature & $T_{0}$ & - & $21.51^{\circ} \mathrm{C}$ \\
Server flow rate & $Q_{s}$ & $Q_{s}=Q_{t} / 4$ & $4.5 \frac{\mathrm{m}^{3}}{\mathrm{~s}}$ \\
Server heat generation & $P_{s}$ & $P_{s}=\rho c_{p} Q_{s} \Delta T$ & $42.2 \mathrm{~kW}$ \\
Perforated tiles porosity & $\sigma_{t}$ & - & $50 \%$ \\
Rack porosity & $\sigma_{s}$ & - & $35 \%$ \\
\hline
\end{tabular}

intake temperature, the average cold aisle enclosure temperature as the entrance temperature of the servers, and the average hot aisle enclosure temperature as the output temperature of the servers.

\section{Mathematical formulation}

In this section, firstly to simulate the incompressible fluid flow and heat transfer, the governing equations are described, then the dimensionless temperature indices that are important for data center analysis in minimizing the by-pass flow, recirculation flow, and eliminating excessive cold points and hotspots are introduced. Note that in this study the natural convection has been ignored and the results of the free convection assumption can be investigated in future works.

\subsection{Governing equations and numerical methods}

The calculations of the governing equations of the simulated data center have been used in the 6SigmaDCX software and the fundamental equations have been solved using the code of this program in the steadystate, incompressible, and turbulence $3 \mathrm{D}$ domain. In this numerical simulation, to solve the governing equations, the finite volume method and for the accuracy of the computations, a second-order upwind method has been used to discretize the advection terms. Because of the low Mach number and constant volume of supplied air, the working fluid is considered to be incompressible. The SIMPLE algorithm is used to make velocity terms dependent of pressure terms. In fact, for coupling velocity and pressure to solve the discretized equations, this algorithm used the relationship between pressure and velocity corrections to satisfy the continuity and conveys the real pressure. With these assumptions, conversations of mass reduces to:

$$
\nabla \cdot(\underline{V})=0
$$

The RANS (Reynolds Averaged Navier Stokes) form of the governing equations is used to create the effect of the turbulence. The time-averaged conservation of momentum equation for an incompressible and
Newtonian fluid is:

$$
\rho \frac{D \underline{V}}{D t}=-\nabla P+\underline{\nabla} \cdot\left[\left(\nu+\nu_{t}\right) \nabla \underline{V}\right]+\rho \underline{g} .
$$

The turbulent form of the conversation of the energy equation in terms of time-averaged variables including server heat source is as follows:

$$
\frac{D \underline{T}}{D t}=\underline{\nabla} \cdot\left[\left(\frac{\nu}{\operatorname{Pr}}+\frac{\nu_{t}}{\operatorname{Pr}_{t}}\right) \nabla \underline{T}\right]+\dot{q}
$$

where $T$ is the temperature, $\operatorname{Pr}$ is the Prandtl number, and $q$ is volumetric heat content per unit mass. Note that all parameters in Eqs. (2) and (3) are averaged parameters.

The above equations are solved numerically with CFD-solver of 6SigmaDCX software under the boundary conditions mentioned in Table 2 . In all simulations, the $k$-epsilon turbulence model is used to solve the Reynolds stresses. In this model, it is assumed that the turbulence viscosity $\left(\nu_{t}\right)$ is only a function of $k$ and $\varepsilon$, where $k$ is the turbulent kinetic energy, and $\varepsilon$ is the turbulent dissipation.

\subsection{Performance parameters indices}

The use of temperature indices helps to understand the efficiency and performance of air distribution. A complete distribution of the RCI has been performed by Herrlin [25]. This is a benchmark index that shows the intake temperature of the rack and it is very important for the continuous operation of the data center [25]. Figure 6 shows the allowable and recommended range for rack intake temperature for the design conditions according to the ASHRAE (American Society

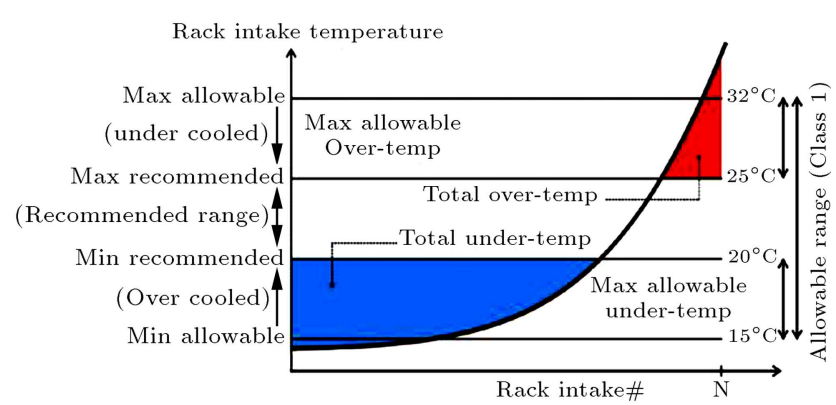

Figure 6. Temperature ranges according to ASHRAE standard. 
of Heating and Air-Conditioning Engineers) standard. Overheating temperature conditions occur when one or more intake temperatures are greater than the maximum recommended temperature. Similarly, under temperature conditions occur when one or more intake temperatures drop below the minimum recommended temperature. The RCI index contains two relationships of $R C I_{\text {High }}$ and $R C I_{\text {Low }}$ to measure the difference in overheating temperatures and the difference in lower temperatures, respectively. They are defined in the following relationships:

$$
\begin{aligned}
& R C I_{\text {High }} \\
& =100 \times\left[1-\frac{\text { Total overtemperature }}{\text { Max allowable overtemperature }}\right] \\
& =100 \times\left[1-\frac{\sum_{1}^{n}\left(T_{i}-T_{\max -r e c}\right)_{T_{i}<T_{\max -r e c}}}{n \times\left(T_{\max -a l l}-T_{\max -r e c}\right.}\right], \\
& R C I_{\text {Low }} \\
& =100 \times\left[1-\frac{\text { Total undertemperature }}{\text { Max allowable undertemperature }}\right] \\
& =100 \times\left[1-\frac{\sum_{1}^{n}\left(T_{\min -r e c}-T_{i}\right)_{T_{i}<T_{\min -r e c}}}{n \times\left(T_{\min -r e c}-T_{\min -a l l}\right)}\right],
\end{aligned}
$$

where $R C I_{\text {High }}$ is $100 \%$, which indicates that there are no overheating temperatures and all racks are cooled according to the ASHRAE standard [27]. The lower percentage indicates the probability that racks will experience temperatures above the maximum recommended temperature. A value $R C I_{\text {High }}$ in the range of $91 \%-96 \%$ is an acceptable range for operation [27]. One of the ways to improve this index is to increase the supply airflow rate and lower the supply airflow temperature, which is also due to an increase in energy consumption [28].

RTI is a measure of the energy consumption performance of the air management system. This index is defined as Eq. (6) [26]:

$$
R T I=\left[1-\frac{T_{\text {return }}-T_{\text {supply }}}{\Delta T_{\text {equipment }}}\right] \times 100 .
$$

The RTI is the ratio of total airflow through the CRACs to the total airflow through the IT-equipment. A value of RTI above $100 \%$ shows hot air re-circulation and the rising in rack intake temperatures. Also, values less than $100 \%$ indicate the cold air by-pass and thus reduce the return temperature to CRACs. Therefore, the optimum value for RTI is $100 \%$. With closing the aisle enclosure, this index is optimized.

SHI is the ratio of heat gained by air before entering the racks and heat gained by air leaving the rack exhaust. By considering the mass flow rates at the inlet and outlet of each rack which is equal, SHI can be written as the ratio of enthalpy rise due to infiltration in cold aisle to total enthalpy rise at the rack exhaust. RHI is considered as a complement to SHI $(S H I+R H I=1)$, where the RHI is defined as the ratio between total heat extractions by the CRAC units to the total enthalpy rise at the rack exhaust. These indexes are defined by equations as follow:

$$
\begin{aligned}
& S H I=\frac{\delta Q}{Q+\delta Q}, \\
& R H I=\frac{Q}{Q+\delta Q},
\end{aligned}
$$

where:

$$
\begin{aligned}
& Q=\sum_{i}^{n} \sum_{j}^{n} m_{i, j}^{r} c_{p}\left[\left(T_{\text {out }}^{r}\right)_{i, j}-\left(T_{\text {in }}^{r}\right)_{i, j}\right], \\
& \delta Q=\sum_{i}^{n} \sum_{j}^{n} m_{i, j}^{r} c_{p}\left[\left(T_{\text {in }}^{r}\right)_{i, j}-T_{\text {ref }}\right],
\end{aligned}
$$

where $Q$ is total heat dissipation from components and $\delta Q$ is the rise in enthalpy of cold air before entering the racks. In Eqs. (9) and (10), $m_{i, j}^{r}$ is the mass flow of air through the $i$ th rack in the $j$ th row of the racks, $\left(T_{\text {out }}^{r}\right)_{i, j}$ and $\left(T_{i n}^{r}\right)_{i, j}$ are the average outlet and inlet temperature from the $i$ th rack in the $j$ th row of the racks. $T_{r e f}$ is the inlet air temperature from the tile side [24]. If SHI is high, it indicates that the intake temperature is high which may be due to the recirculation or mixing of the air before it enters the rack. A low value of RHI is an indication of rack exhaust hot air mixing with cold air inside the cold aisle. The ideal optimum value of SHI and RHI are 0 and 1 respectively, but practical values are 0.2 and 0.8 [24].

\section{Grid independency and model validation}

The aim of the grid refinement study is to achieve a minimum size that does not affect the numerical results and has an independent mesh size. The numerical grid generated by the software is shown in Figure 7(a). Grid independency solutions are modeled in 3 different mesh sizes and the results of dimensionless temperature indices are illustrated in Table 3 .

Also, in Figure 7(b) the mean intake temperature per rack for the cell numbers 2043630, 3998421, and 4392839 are compared where error bars are less than $10 \%$. According to these results, the cell number of 2043630 with a mesh size of $0.2 \mathrm{~m}$ is sufficient to continue the calculations.

To validate the present numerical model, temperature contours obtained from the numerical simulation were analyzed and compared with the values obtained from experimental measurements with Testo 605-H1 digital thermometer. The racks are numbered as shown 
Table 3. Independency analysis of the grid of temperature indices.

\begin{tabular}{cccccc}
\hline Cell number & RTI & RCI-High & RCI-Low & SHI & RHI \\
\hline 2043630 & 76 & 80.4 & 100 & 0.563 & 0.422 \\
3998421 & 76.8 & 81 & 100 & 0.551 & 0.431 \\
4392839 & 76.56 & 81.05 & 100 & 0.568 & 0.428 \\
\hline
\end{tabular}

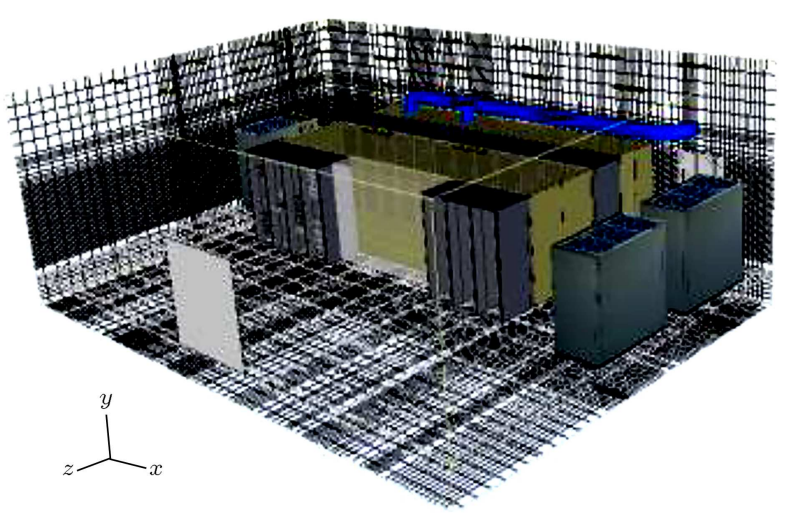

(a)

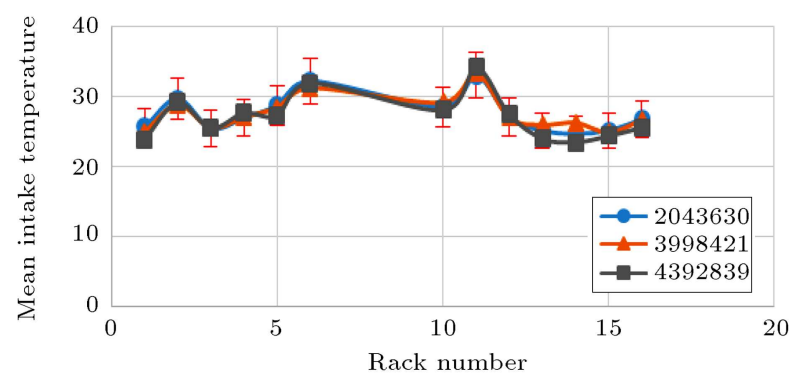

(b)

Figure 7. (a) Numerical grid by the software. (b) Mesh analysis of the mean intake temperature of racks.

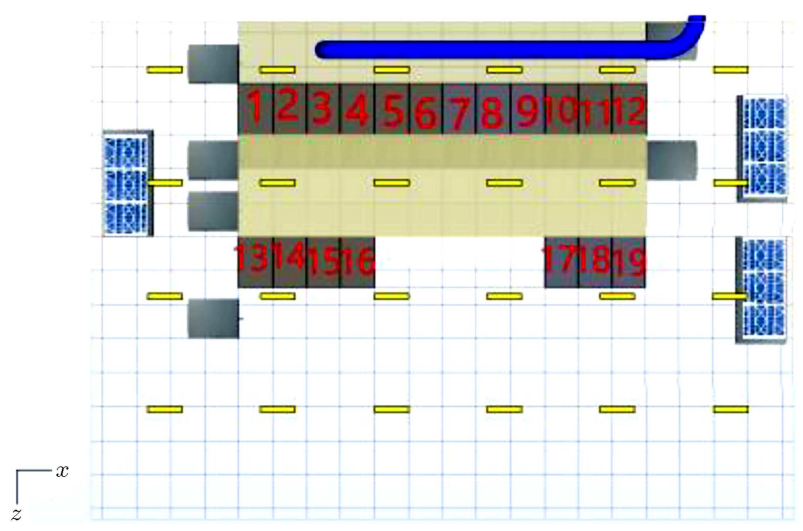

Figure 8. Numbering of racks.

in Figure 8 and the intake and outlet temperatures of racks at the height of $1.8 \mathrm{~m}$ from the raised floor which are measured with a thermometer are compared with numerical simulation results. These results are illustrated in Figures 9 and 10 and error bars are

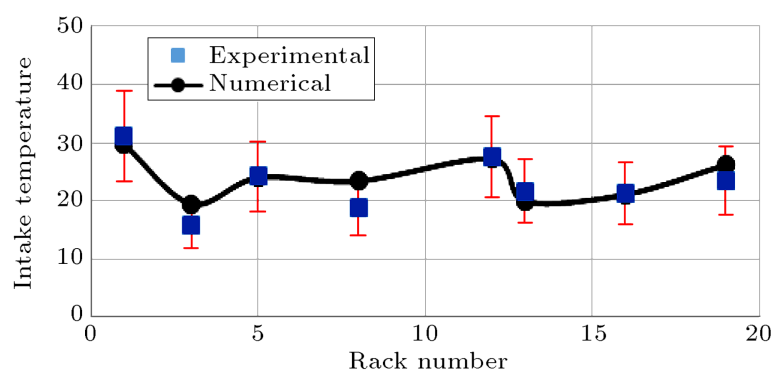

Figure 9. Comparison of experimental and numerical intake temperature at a height of $1.8 \mathrm{~m}$.

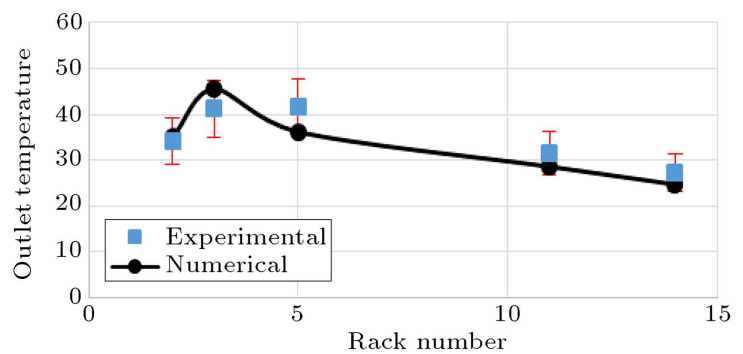

Figure 10. Comparison of experimental and numerical outlet temperature at the height of $1.8 \mathrm{~m}$.

Table 4. Error amount for temperature comparison.

\begin{tabular}{cccc}
\hline Error amount & $\begin{array}{c}\text { Min } \\
\text { error }\end{array}$ & $\begin{array}{c}\text { Max } \\
\text { error }\end{array}$ & $\begin{array}{c}\text { Mean } \\
\text { error }\end{array}$ \\
\hline Intake temperature & $0.8 \%$ & $19.5 \%$ & $8.3 \%$ \\
Outlet temperature & $2.5 \%$ & $14.9 \%$ & $9.3 \%$ \\
\hline
\end{tabular}

calculated and shown in Table 4. As shown, the mean error is less than 10\%, Therefore there is a good agreement between the numerical solution and experimental measurements.

\section{Results and discussion}

Experimental and numerical simulations are performed for the model of AUT high-speed processing center and the temperature distributions in the data center have been obtained and analyzed. The data center performance indices are calculated using the temperature distribution results and the results of the experimental and numerical solutions are compared. In the following sections, to improve the cooling and airflow performance, a cold aisle enclosure with decreasing supply airflow temperature and a hot aisle enclosure 
with return air from the plenum ceiling have been used. In the end, the best case for the AUT data center is introduced.

\subsection{Results of experimental measurements}

To perform an empirical simulation of the data center using the Testo thermometer, the temperature of 39 points of the data center, i.e., the intake temperature of each rack at $0.2,1$, and $1.8 \mathrm{~m}$ above-raised floor is measured. Note that these measurements in contrast to the temperature measurements, performed in Section 4 to validate the numerical results, are measured at a distance of $5 \mathrm{~cm}$ from the input and output of each rack server. The measurement procedure has been repeated three times at each of three heights and the mean data have been reported. Note that for racks $7,8,9,17,18$, and 19 because of being empty of any equipment, no temperature measurements were taken. These cabinets fill up with some blocks that separates the inflows on the front at the cold aisle from the outflows on the back at the side of the hot aisle. The blanking comprised some solid obstructions that have been modeled to remove the gaps between the servers and segregate the air paths to prevent internal recirculation. Therefore, the effective open area of these cabinets reduced approximately to zero, and the recirculation of hot air from these cabinets to the cold aisle enclosure reached to lowest possible volume which affected the thermal performance metrics.

The maximum intake temperature was measured for the first and second row racks (Figure 11). The allowable temperature range for server processing according to the ASHRAE Class A1 Temp [27] is between 18 and 27 degrees, which is specified in Figure 11 by the green area. According to this figure, servers located at a height of $1.8 \mathrm{~m}$ from racks $1,2,3,13,14$, and 15 are within the permitted temperature range and the rest of the servers at this height are not within the accepted standard of ASHRAE. At a height of $1 \mathrm{~m}$, only servers for racks $12,13,14$, and 15 are located

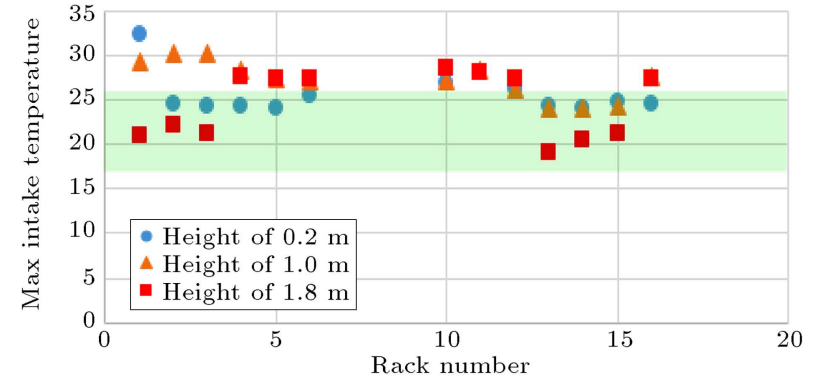

Figure 11. Maximum intake temperature of the experimental measurements and ASHRAE Class A1.

within the acceptable range. At the height of $0.2 \mathrm{~m}$ from the raised floor servers for racks $2,3,4,5,12,13$, 14,15 , and 16 work at the standard temperature range of ASHRAE.

Based on the total volume of air produced by the CRAC units $\left(m_{i, j}^{r}\right)$ fo the IT equipment in the server room and the supply air temperature $\left(T_{r e f}\right)$, the average cold aisle enclosure temperature as the entrance temperature to the servers $\left(T_{i n}^{r}\right)_{i, j}$ and the average hot aisle enclosure temperature as the output temperature of the servers $\left(T_{\text {out }}^{r}\right)_{i, j}$ and the placement of these values in the Eqs. (7) and (8), the SHI and RHI indexes are calculated according to Table 5 .

In Table 6, the RCI-Low is calculated using Eq. (5). Since the minimum recommended temperature $\left(T_{\min -r e c}\right)$ and inlet temperature to the racks are equal, then the RCI index is $100 \%$ indicating no temperature is less than the limit. The minimum allowable and minimum recommended temperatures are obtained according to Figure 6 and experimental temperature measurements.

In Table 7, the RCI-High index is calculated according to Eq. (4) and the maximum allowable and maximum recommended temperatures are obtained according to Figure 6 and experimental temperature measurements. The RTI index is calculated according to Eq. (6). In this equation, the supply air temperature $\left(T_{\text {supply }}\right)$ is obtained by averaging the outlet tempera-

Table 5. Supply Heat Index (SHI) and Return Heat Index (RHI) calculations from experimental results.

\begin{tabular}{ccccccc}
\hline $\begin{array}{c}\text { Airflow } \\
\text { rate } \\
\left(\boldsymbol{m}_{\boldsymbol{i}, \boldsymbol{j}}^{\boldsymbol{r}}\right)\end{array}$ & $\begin{array}{c}\text { Specific heat } \\
\text { transfer } \\
\left(\boldsymbol{C}_{\boldsymbol{p}}\right)\end{array}$ & $\begin{array}{c}\text { Supply air } \\
\text { temperature } \\
\left(\boldsymbol{T}_{\boldsymbol{R} e f}\right)\end{array}$ & $\begin{array}{c}\text { Intake } \\
\text { temperature } \\
\left(\boldsymbol{T}_{i n}^{\boldsymbol{r}}\right)_{\boldsymbol{i}, \boldsymbol{j}}\end{array}$ & $\begin{array}{c}\text { Output } \\
\text { temperature } \\
\left(\boldsymbol{T}_{\text {out }}^{\boldsymbol{r}}\right)_{\boldsymbol{i}, \boldsymbol{j}}\end{array}$ & $\mathbf{S H I}$ & $\mathbf{R H I}$ \\
\hline $18 \frac{\mathrm{m}^{3}}{\mathrm{~s}}$ & $1005 \frac{\mathrm{J}}{\mathrm{kg} \cdot{ }^{\circ} \mathrm{k}}$ & $21.51^{\circ} \mathrm{C}$ & $27.31{ }^{\circ} \mathrm{C}$ & $34.99^{\circ} \mathrm{C}$ & 0.43 & 0.569 \\
\hline
\end{tabular}

Table 6. RCI-Low calculation from experimental results.

\begin{tabular}{cccc}
\hline $\begin{array}{c}\text { Intake temperature } \\
\left(\boldsymbol{T}_{\boldsymbol{i}}<\boldsymbol{T}_{\min }-\mathrm{rec}\right)\end{array}$ & $\begin{array}{c}\text { Minimum allowable } \\
\text { temperature } \\
\left(\boldsymbol{T}_{\min -\text { all })}\right.\end{array}$ & $\begin{array}{c}\text { Minimum recommended } \\
\text { temperature } \\
\left(\boldsymbol{T}_{\min -\text { rec }}\right)\end{array}$ & RCI-Low \\
\hline $18^{\circ} \mathrm{C}$ & $15^{\circ} \mathrm{C}$ & $18^{\circ} \mathrm{C}$ & $100 \%$ \\
\hline
\end{tabular}


Table 7. RCI-High calculation from experimental results.

\begin{tabular}{cccc}
\hline $\begin{array}{c}\text { Intake temperature } \\
\left(\boldsymbol{T}_{\boldsymbol{i}}<\boldsymbol{T}_{\max -\text { rec }}\right)\end{array}$ & $\begin{array}{c}\text { Maximum allowable } \\
\text { temperature } \\
\left(\boldsymbol{T}_{\max -\text { all })}\right.\end{array}$ & $\begin{array}{c}\text { Maximum recommended } \\
\text { temperature } \\
\left(\boldsymbol{T}_{\max -\text { rec }}\right)\end{array}$ & RCI-High \\
\hline $27.31^{\circ} \mathrm{C}$ & $32^{\circ} \mathrm{C}$ & $27^{\circ} \mathrm{C}$ & 93.8 \\
\hline
\end{tabular}

Table 8. Return Temperature Index (RTI) calculation from experimental results.

\begin{tabular}{cccc}
\hline $\begin{array}{c}\text { Supply air } \\
\text { temperature } \\
\left(\boldsymbol{T}_{\text {supply }}\right)\end{array}$ & $\begin{array}{c}\text { Input and output } \\
\text { temperature difference } \\
\left(\boldsymbol{\Delta} \boldsymbol{T}_{\text {equipment }}\right)\end{array}$ & $\begin{array}{c}\text { Return } \\
\text { temperature } \\
\left(\boldsymbol{T}_{\text {return }}\right)\end{array}$ & RTI \\
\hline $21.51^{\circ} \mathrm{C}$ & $7.68^{\circ} \mathrm{C}$ & $23.9^{\circ} \mathrm{C}$ & 68.88 \\
\hline
\end{tabular}

ture from the CRAC units. The difference in input and output temperature to the racks $\left(\Delta T_{\text {equipment }}\right)$ is also the average temperature difference between the cold aisle and hot aisle $\left(T_{\text {out }}^{r}-T_{i n}^{r}\right)$ according to Table 5 . Return temperature $\left(T_{\text {return }}\right)$ is calculated by averaging the recorded temperatures of the return valves of each air-conditioner unit (Table 8).

\subsection{Results of numerical solution}

The issue has been solved with the help of 6SigmaDCX software relating to the boundary and initial conditions which were mentioned in Section 2. Contours of temperature at the height of $0.2 \mathrm{~m}, 1 \mathrm{~m}$, and $2 \mathrm{~m}$ from the raised floor are shown in Figure 12(a), (b), and (c), respectively.

According to Figure 12(b), the recirculation of hot air from 2U-Berbon supermicro $1400 \mathrm{~W}$ servers to the cold aisle enclosure occurs at the height of $1 \mathrm{~m}$ from the raised floor in racks of the first row numbered 2, $3,6,11$, and 12 . The recirculation of hot air for rack number 2 is well illustrated with velocity contours in Figure 13.

The pressure contour is shown in Figure 14 at the height of $1 \mathrm{~m}$ from the raised floor. It is observed that the pressure on the side of the hot aisle enclosure was higher than the pressure on the side of the cold aisle enclosure or the input of the racks, which causes the recirculation of hot air and make a negative pressure difference in the output of 30 devices of the first row 2U-Bourbon supermicro servers from the racks (Figure 12(b)).

ASHRAE Class A1 Temp compliance for each rack at 3 heights is shown in Figure 15, which in some cases is not in the accepted and green area. ASHRAE Class A1 Temp measures the maximum intake temperature compared to the standard range. The red and orange colors show the racks that experience temperatures above the maximum recommended temperature.

In Figure 15, the red and orange color at a height of $1 \mathrm{~m}$ from the raised floor in the racks is due to the

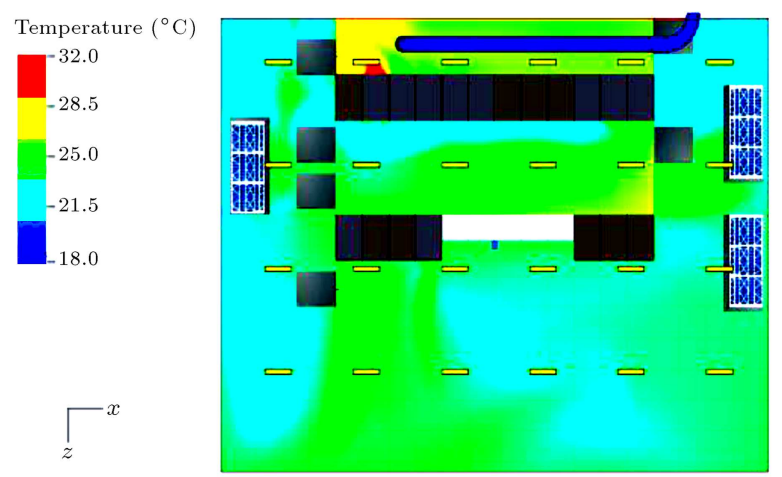

(a) Height of $0.2 \mathrm{~m}$ from raised floor

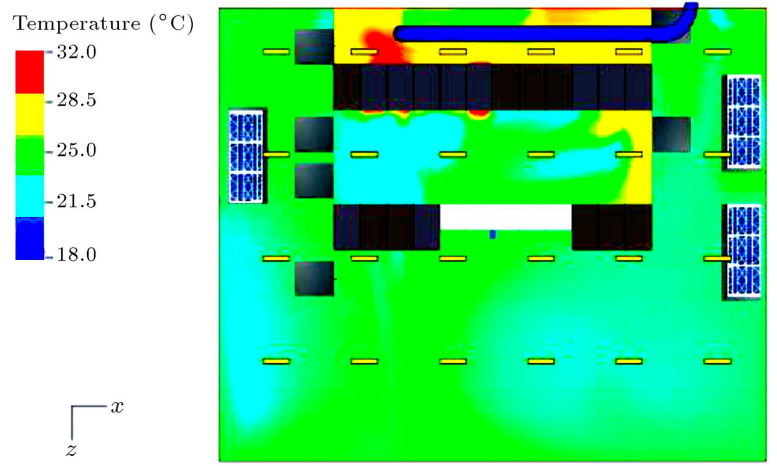

(b) Height of $1 \mathrm{~m}$ from raised floor

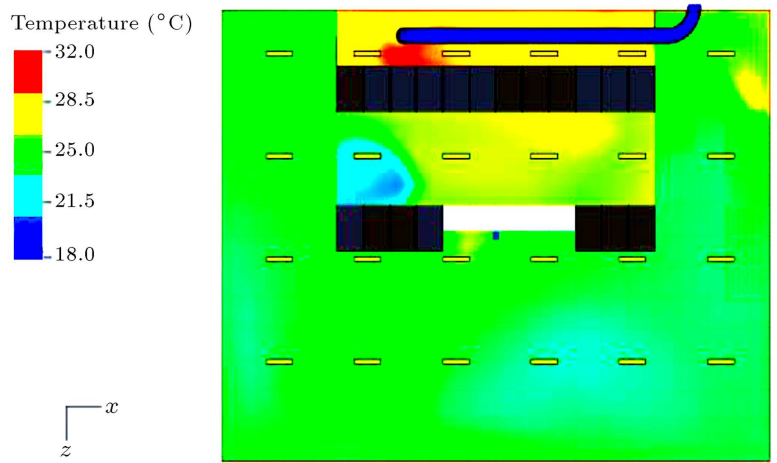

(c) Height of $2 \mathrm{~m}$ from raised floor

Figure 12. (a) Temperature contours at a height of $0.2 \mathrm{~m}$. (b) Temperature contours at a height of $1 \mathrm{~m}$. (c) Temperature contours at a height of $2 \mathrm{~m}$. 


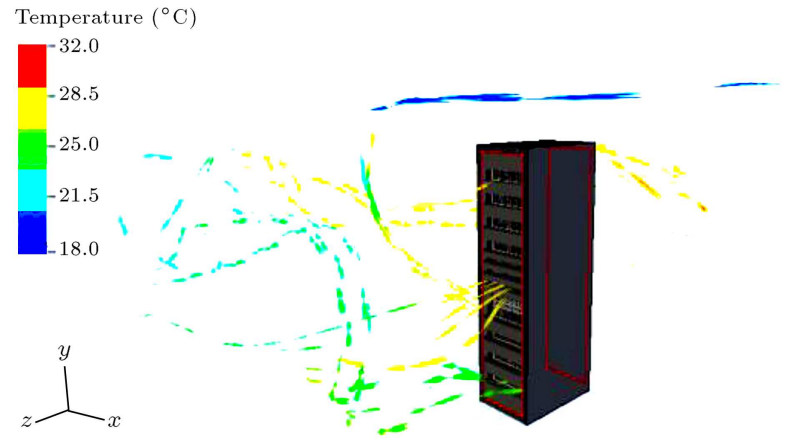

Figure 13. Velocity contours for rack number 2.

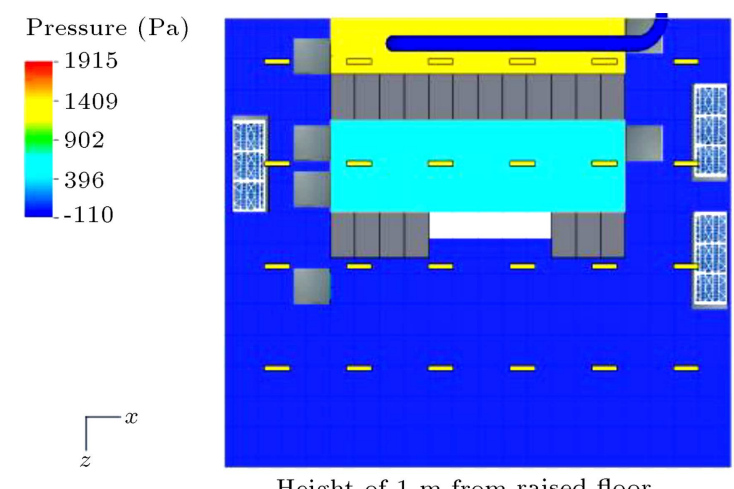

Height of $1 \mathrm{~m}$ from raised floor

Figure 14. Pressure contour at a height of $1 \mathrm{~m}$.

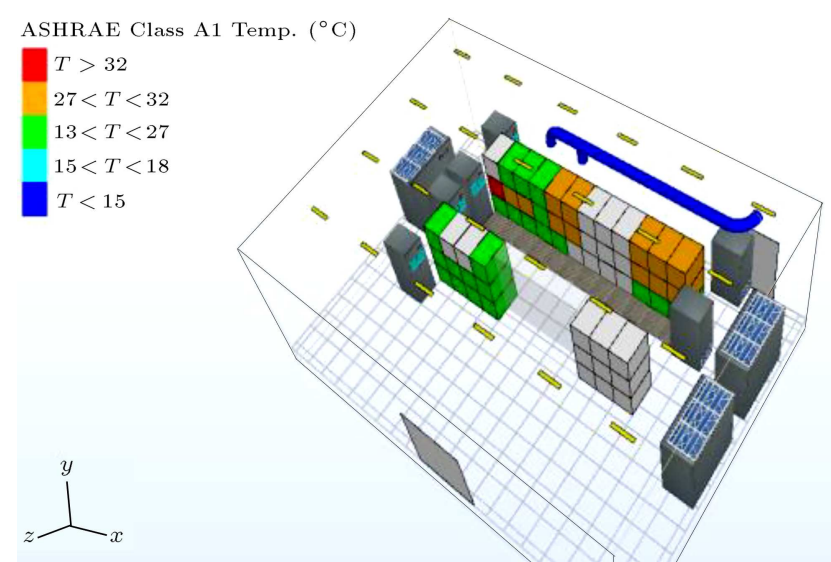

Figure 15. ASHRAE 2011 Class A1 TEMP.

hot air recirculation to the cold aisle as is shown in Figure 12(b).

The data center performance parameter indices are calculated automatically with software (Table 9 ). The high value of SHI (0.568) compared to the optimum value (zero) indicates the high intake temperature of the racks. Also, RHI is below the optimum value of 1 , indicating the mixing of hot air from the output of the rack with cold air within the cold aisle. The 100 value of RCI-Low indicates that there is no lower temperature than the permissible limit, however, a low percentage of RCI-High supports this hypothesis that the intake temperature experienced by racks was higher than the
Table 9. Room performance indices from the numerical solution.

\begin{tabular}{ccccc}
\hline SHI & RHI & RCI-Low & RCI-High & RTI \\
\hline 0.568 & 0.422 & 100 & 81.05 & 76.56 \\
\hline
\end{tabular}

recommended temperature. The RTI less than 100, indicates by-pass cold air.

\subsection{Comparison of numerical and experimental simulation of the data center}

After numerical simulating of the data center with 6SigmaDCX software and experimental simulating through measuring the temperature at different points of the data center, in this section, we compared the results of both simulations.

ASHRAE Class A1 Temp for numerical and experimental results are presented in Figures 11 and 15, respectively. At the height of $0.2 \mathrm{~m}$ from the raised floor, in numerical solutions, all servers are operated in the standard temperature range, but according to the experimental results, servers at racks number 1 and 10 are not in the accepted area of the ASHRAE standard. At the height of $1 \mathrm{~m}$ from the raised floor, from numerical results, racks number 1, 2, 13, 14, 15, and 16 are in the accepted area of the ASHRAE standard. However, for experimental results at this height, racks number $12,13,14$, and 15 falls into the standard temperature range. By comparing the temperature compliance obtained from the numerical solution and the experimental measurements at a height of $1.8 \mathrm{~m}$ from the raised floor, it becomes clear that the only difference is that racks 4 and 16 are located in the acceptable area in the numerical solution, while according to Figure 11 for experimental simulation, these racks are not in the accepted area of the ASHRAE standard.

According to Tables 5 and 9, the comparison of the SHI and RHI for numerical and experimental solutions is shown in Figure 16. According to this

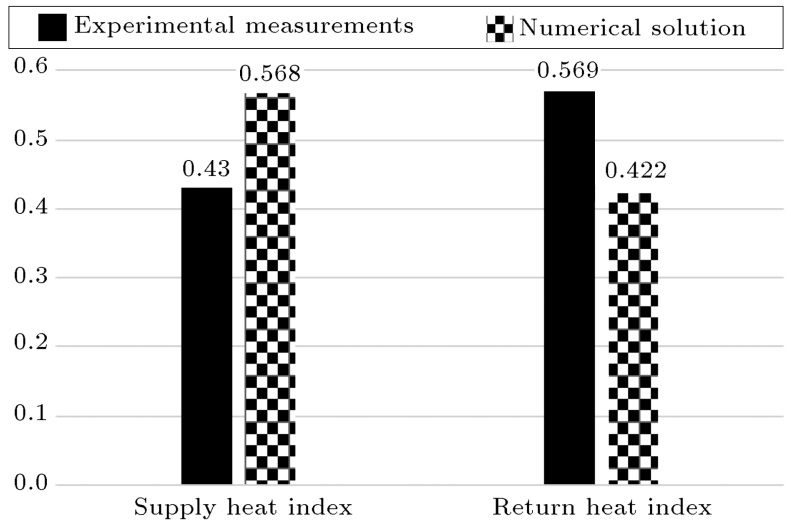

Figure 16. Comparison of Supply Heat Index (SHI) and Return Heat Index (RHI) for numerical and experimental solutions. 


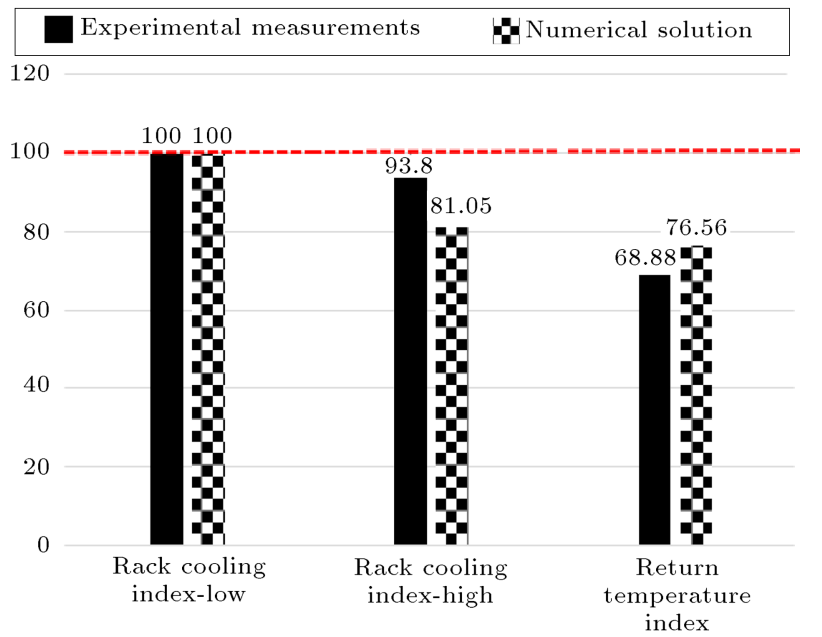

Figure 17. Comparison of Rack Cooling Index (RCI) and Return Temperature Index (RTI) for numerical and experimental solutions.

figure, in the numerical solution, SHI has an error of about $24 \%$ compared to the SHI in the experimental solution. The RHI for the experimental solution also has an error of about $25 \%$ compared to the RHI in the numerical solution. The reason for the high error of these two indices is that in the experimental solution for the cold and hot aisle temperatures, the average temperatures are measured at three heights, while in the numerical solution the average of all heights for the hot and cold aisles temperatures is considered.

According to Tables 6-9, the minimum and maximum RCI and RTI of the numerical solution and experimental measurements are shown in Figure 17. Given that, none of the racks are exposed to temperatures below the minimum recommended temperature of ASHRAE, in both numerical and experimental solutions, RCI-Low would be 100. But, RCI-High for the experimental solution had an error of about $13 \%$ compared to the numerical solution. In the numerical solution, RTI had also an error of about $10 \%$ compared to the RTI in the experimental solution. These indices have a low error since supply air temperature in both numerical and experimental solutions has been recorded from the CRACs units and the only error resulted from the error in measuring the temperature difference of equipment using temperature averaging for cold and hot aisles at three heights.

\subsection{Enhancement of data center thermal management using cold aisle containment}

Figure 18 shows the amount of air required for each cabinet. Considering that the volume of air required to cool the second-row rack servers is more than the volume of the air required to cool other racks, perforated tiles are provided in front of racks 13, 14, 15 , and 16 to provide the required airflow.

In the cold aisle enclosure model to reduce the

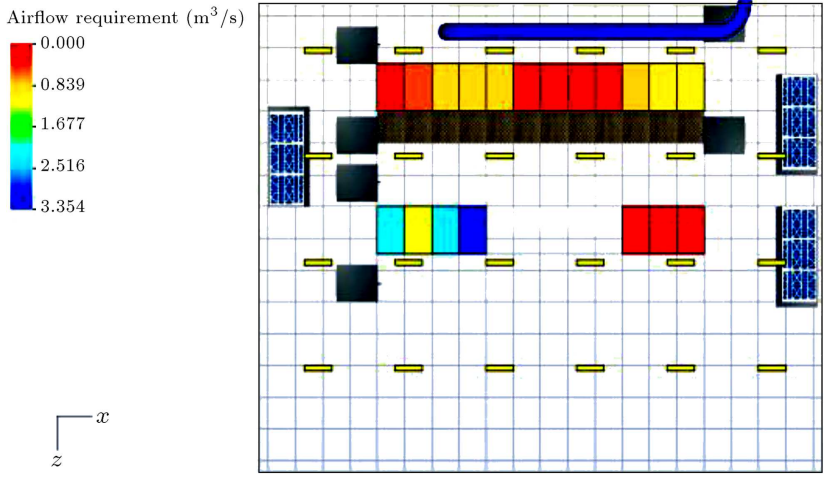

Figure 18. Airflow requirement for each rack.

intake temperature to servers within the standard range of ASHRAE, CRACs that can supply air at a temperature of $18^{\circ} \mathrm{C}$ are replaced and floor standing air conditioners have been removed from the data center. These air conditioner units were added to increase the amount of supply air to improve the RCI-High index of the racks of the data center, but this index did not reach its optimal value (Table 9 ).

\subsection{Enhancement of data center thermal management using hot aisle containment with return flow from ceiling plenum}

To reduce the re-circulation airflow and intake temperature to the racks, the data center is simulated once more using a hot aisle enclosure with return airflow from the ceiling plenum with a height of $0.5 \mathrm{~m}$. In this case, instead of ventilating hot airflow from the hot enclosure by the blower, by creating a ceiling plenum and ducting from the hot aisle enclosure to the CRAC units return valves, hot air returned to the air conditioners. For this model, the same specification of the CRAC units is used as the primary and base model of the data center. Also, in this case, the lights are installed on the ceiling plenum instead of the room ceiling.

\subsection{Comparison of the results of different configuration models of the data center}

In this section, the results of the primary and base model of the Amirkabir University server room are compared with the results of the cold aisle enclosure and hot aisle enclosure models. According to Table 10, it can be seen that the cooling system of the base model uses only $26 \%$ of its cooling capacity, while in the two

Table 10. Cooling system information.

\begin{tabular}{lcc}
\hline Model & $\begin{array}{c}\text { Total nominal } \\
\text { cooling capacity }\end{array}$ & $\begin{array}{c}\text { Total ACU } \\
\text { cooling } \\
\text { in use }\end{array}$ \\
\hline Base & $195 \mathrm{~kW}$ & $51.26 \mathrm{~kW}$ \\
Cold aisle enclosure & $120 \mathrm{~kW}$ & $59.52 \mathrm{~kW}$ \\
Hot aisle enclosure & $120 \mathrm{~kW}$ & $59.26 \mathrm{~kW}$ \\
\hline
\end{tabular}


Table 11. Comparison of heat load breakdown.

\begin{tabular}{lcccc}
\hline Model & $\begin{array}{c}\text { Total room load } \\
(\mathbf{k W})\end{array}$ & $\begin{array}{c}\text { Equipment load } \\
(\mathbf{k W})\end{array}$ & $\begin{array}{c}\text { Cooling system load } \\
(\mathbf{k W})\end{array}$ & $\begin{array}{c}\text { Lighting load } \\
(\mathbf{k W})\end{array}$ \\
\hline Base & 65 & 42.2 & 13.2 & 9.6 \\
Cold aisle enclosure & 59.6 & 42.2 & 7.8 & 9.6 \\
Hot aisle enclosure & 59.2 & 42.2 & 7.8 & 9.2 \\
\hline
\end{tabular}

Table 12. Comparison of airflow.

\begin{tabular}{lccc}
\hline Model & $\begin{array}{c}\text { Total cooling airflow } \\
\left(\frac{\mathrm{m}^{3}}{\mathrm{~s}}\right)\end{array}$ & $\begin{array}{c}\text { Total equipment airflow } \\
\left(\frac{\mathrm{m}^{3}}{\mathrm{~s}}\right)\end{array}$ & $\begin{array}{c}\text { Mean cabinet flow } \\
\left(\frac{\mathrm{m}^{3}}{\mathrm{~s}}\right)\end{array}$ \\
\hline Base & 18 & 15.2 & 0.8 \\
Cold aisle enclosure & 9 & 8.3 & 0.4 \\
Hot aisle enclosure & 10.8 & 9.4 & 0.4 \\
\hline
\end{tabular}

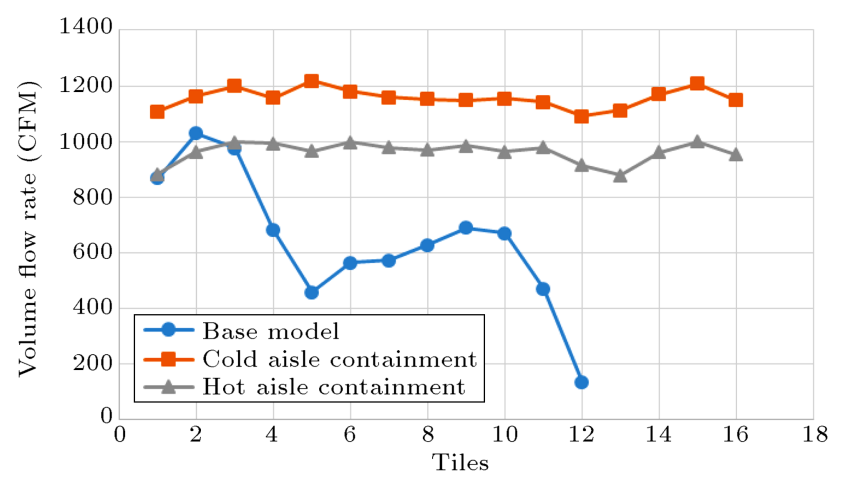

Figure 19. Comparison of floor flow rates for models.

other models about $50 \%$ of the capacity of the cooling system is used.

According to Table 11, 3.9\% of the total room load relates to the cooling system in the base model, while in the other two models, due to the removal of standing air conditioner units, the load on the cooling systems is decreased to $7.8 \mathrm{~kW}$. In the base model of the data center, to improve the RCI-high index, the total airflow of supplying air was increased by adding standing air conditioners in the cold and hot enclosures. According to Table 12, due to the high total equipment airflow in the base model especially super-micro servers in the second row experience about $50 \%$ more airflow than defined airflow for them. In the cold aisle enclosure and hot aisle enclosure models the total airflow supplied by CRAC units have been decreased.

Figure 19 shows the volume of airflow per tile for each case. It is observed that the number of tiles of the base model is 12 and in the second row, there is no tile setup for any of the racks. The figure shows that the distribution of airflow rate of cold aisle containment and hot aisle containment models are more uniform than the base model of the data center. This uniformity reduces both cold air bypass and hot air recirculation of the racks. Note that, the reduction of the supply

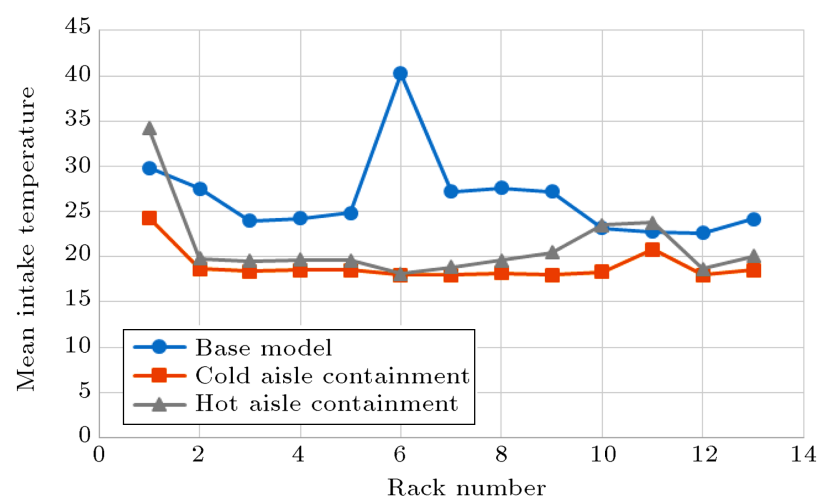

Figure 20. Comparison of mean intake temperature for models.

airflow rates in the perforated tiles creates hot air recirculation (see Figure $12(\mathrm{~b})$ ).

In Figure 20, the average intake air temperature of the racks of all three models is compared. The mean intake temperature of the two models of cold aisle enclosure and hot aisle enclosure is in acceptable range of ASHRAE standard, which the mean intake temperature of the base model of the data center are higher and not acceptable. The cold aisle enclosure model has a lower mean temperature due to non-mixing exhaust air from racks relative to the other models. By comparing the temperature of the servers in the data center in Table 13, it is seen that the number of servers that are not cooled within the ASHRAE standard in the hot aisle enclosure model is low and this model is an appropriate model for the data center.

\section{Conclusions}

AUT data center was investigated through experimental measurements and numerical solutions and the data center performance indices were calculated using the temperature distribution results. The results of the temperature distribution of the experimental and 
Table 13. Comparison of equipment temperatures for models.

\begin{tabular}{lcc}
\hline Model & $\begin{array}{c}\text { Number of IT equipment } \\
\text { over ASHRAE recommended }\end{array}$ & $\begin{array}{c}\text { Number of IT equipment } \\
\text { over ASHRAE allowable }\end{array}$ \\
\hline Base & 80 & 37 \\
Cold aisle enclosure & 12 & 10 \\
Hot aisle enclosure & 9 & 6 \\
\hline
\end{tabular}

numerical solutions are compared. It was observed that Supply Heat Index (SHI) and Return Heat Index (RHI) indices have an error of about $24 \%$ and $25 \%$, respectively, in numerical solution compared to the experimental measurement. In both numerical and experimental solutions, RCI-Low was 100 because none of the racks are exposed to temperatures below the minimum recommended temperature of ASHRAE. But RCI-High and Return Temperature Index (RTI) for the experimental solution had an error of about $13 \%$ and $10 \%$ respectively compared to the RCI-High and RTI in the numerical solution. According to Figure 12(b), the recirculation of hot air to the cold aisle enclosure has occurred at the height of $1 \mathrm{~m}$ from the raised floor in racks of the first row numbered $2,3,6,11$, and 12 in the base model, because of a negative pressure difference of the output of 30 devices of the first row. To ensure the accuracy of the results, the thermal management of the data center, the cold aisle enclosure that reduces the supply air temperature to 18 degrees, and the hot aisle that returns hot air from the ventilated ceiling to the Computer Room Air Conditioning (CRAC) unit were studied. The results showed that:

- Due to the removal of standing air conditioner units, the load on the cooling systems decreased from $13.2 \mathrm{~kW}$ in the base model to $7.8 \mathrm{~kW}$ in cold aisle enclosure and hot aisle enclosure models. As a result, increasing the power of cooling units is not just a good way to improve the thermal performance of data centers;

- According to Table 12, due to the high total equipment airflow in the base model especially supermicro servers in the second row had about $50 \%$ more airflow than the airflow defined for them, and by increasing the airflow rate the cold air bypass is increased, thereby reducing the RTI to below 100 (see Table 9). This issue has been solved in the cold aisle enclosure and hot aisle enclosure models with a decrease in the total airflow supplied by CRAC units. Therefore, adding the number of cooling units is not a good way to manage airflow in data centers;

- Figure 19 shows that the distribution of airflow rate on perforated tildes of cold aisle enclosure and hot aisle enclosure models are more uniform than the base model of the data center. This uniformity reduces both cold air bypass and hot air recirculation of the racks;

- According to Table 13, the number of servers that are not cooled within the ASHRAE recommended degree (18-27) in the hot aisle enclosure model is low compared with the cold aisle enclosure model and the base model of the data center. Therefore hot aisle enclosure with return air from the plenum ceiling to CRAC units is a more appropriate configuration for the data center.

\section{Nomenclature}

Q Total dissipation from data center components (W)

$C_{p} \quad$ Specific heat of air at constant pressure $(\mathrm{Pa})$

$\nu \quad$ Viscosity

$m \quad$ The mass flow rate of air through a $\operatorname{rack}\left(\frac{\mathrm{m}^{3}}{\mathrm{~s}}\right)$

$T \quad$ Temperature $\left({ }^{\circ} \mathrm{C}\right)$

$N \quad$ Total number of intakes

\section{Superscripts}

$R \quad$ Rack

C CRAC

\section{Subscripts}

In Inlet

out Outlet

Ref CRAC supply

$t \quad$ Turbulence

$i, j \quad$ Cartesian direction

$\max -$ rec Maximum recommended/some guideline or standard

max - all Maximum allowable/some guideline or standard

min - rec Minimum recommended/some guideline or standard

min - all Minimum allowable/some guideline or standard

Return Return air (weighted average) 
Supply Supply air (weighted average)

Equip Rise across the electronic equipment (weighted average)

\section{References}

1. Kurkjian, C. and Glass, J. "Meeting the needs of $24 / 7$ data centers", ASHRAE Journal, 49(2), pp. 24-35 (2007).

2. Patankar, S.V. "Airflow and cooling in a data center", Journal of Heat Transfer, 132, pp. 073001-17 (2010).

3. Masanet, E., Shehabi, A., Lei, N., et al. "Recalibrating global data center energy-use estimates", Science, 367(6481), pp. 984-986 (2020).

4. Lei, N. and Masanet, A.S.E. "Statistical analysis for predicting location-specific data center PUE and its improvement potential", Energy, 201 (2020).

5. Jin, C., Bai, X., and Yang, C. "Effects of airflow on the thermal environment and energy efficiency in raisedfloor data centers: A review", Science of The Total Environment, 695 (2019).

6. Rahmaninia, R., Amani, E., and Abbassi, A. "Computational optimization of a UFAD system using large eddy simulation", Scientia Iranica, 27(6), pp. 28712886 (2019).

7. Hassan, N.M.S., Khan, K., and Rasul, M.G. "Temperature monitoring and CFD analysis of data centre", Procedia Engineering, 56, pp. 551-559 (2013).

8. Nada, S.A. and Elfeky, K.E. "Experimental investigations of thermal management solutions in data centers buildings for different arrangements of cold aisles containments", Journal of Building Engineering, 5, pp. 41-49 (2016).

9. Yuan, X., Wang, Y., Liu, J., et al. "Experimental and numerical study of airflow distribution optimization in high-density data center with flexible baffles", Building and Environment, 140, pp. 128-139 (2018).

10. Nada, S.A.M., Said, A., and Rady, M.A. "CFD investigations of data centers' thermal performance for different configurations of CRACs units and aisles separation", Alexandria Engineering Journal, 55(2), pp. 959-971 (2016).

11. Lyua, C., Chen, G., and Liu, Y. "Enclosed aisle effect on cooling efficiency in small scale data center", In Procedia Engineering, 205, pp. 3789-3796 (2017).

12. Cho, J. and Kim, B.S. "Evaluation of air management system's thermal performance for superior cooling efficiency in high-density data centers", Energy and Buildings, 43(9), pp. 2145-2155 (2011).

13. Huang, Z., Dong, K., Sun, Q., et al. "Numerical simulation and comparative analysis of different airflow distributions in data centers", Procedia Engineering, 205, pp. 2378-2385 (2017).

14. Jiao, Y. and Li, Y. "Thermal analysis for underground data centres in the tropics", In Energy Procedia, Singapore: World Engineers Summit-Applied Energy
Symposium \& Forum: Low Carbon Cities \& Urban Energy Joint Conference, pp. 19-21 (2017).

15. Yuan, X., Xu, X., Liu, J., et al. "Improvement in airflow and temperature distribution with an in-rack UFAD system at a high-density data center", Building and Environment, 168, p. 106495 (2020).

16. Ling, Y.-Z., Zhang, X.-S., Zhang, K., et al. "On the characteristics of airflow through the perforated tiles for raised-floor data centers", Journal of Building Engineering, 10, pp. 60-68 (2017).

17. Karki, K.C. and Patankar, S.V. "Airflow distribution through perforated tiles in raised-floor data centers", Building and Environment, 41(6), pp. 734-744 (2006).

18. Nada, S.A. and Said, M.A. "Comprehensive study on the effects of plenum depths on airflow and thermal management in data centers", International Journal of Thermal Sciences, 122, pp. 302-312 (2017).

19. Schmidt, R. and Iyengar, M. "Comparison between underfloor supply and overhead supply ventilation designs for data center high-density clusters", ASHRAE Transactions, 113(Part 1) (2005).

20. Cho, J., Yang, J., and Park, W. "Evaluation of air distribution system's airflow performance for cooling energy savings in high-density data centers", Energy and Buildings, 68, pp. 270-279 (2014).

21. Priyadumkol, J. and Kittichaikarn, C. "Application of the combined air-conditioning systems for energy conservation in a data center", Energy and Buildings, 68, pp. 580-586 (2014).

22. Chu, W.-X., Hsu, C.-S., Tsui, Y-Y., et al. "Experimental investigation on thermal management for small container data center", Journal of Building Engineering, 21, pp. 317-327 (2019).

23. U.S. Department of Energy and U.S. Data Centers Save Energy Now "Industrial Technologies Program", DOE-Energy Efficiency and Renewable Energy (2009).

24. Sharma, R., Bash, C., and Patel, C. "Dimensionless parameters for evaluation of thermal design and performance of large-scale data centers", Presented at the 8th AIAA/ASME Joint Thermophysics and Heat Transfer Conference (2002).

25. Herrlin, M.K. "Rack cooling effectiveness in data centers and telecom central offices: the rack cooling index (RCI)", ASHRAE Transactions, 111(2), pp. 111 (2005).

26. Herrlin, M.K. "Improved data center energy efficiency and thermal performance by advanced airflow analysis", In Proceedings of Digital Power Forum, pp. 10-12 (2007).

27. TC 9.9 Mission Critical Facilities, Technology Spaces and Electronic Equipment "Thermal guidelines for data processing environments-Expanded data center classes and usage guidance", American Society of Heating, Refrigerating and Air Conditioning Engineers Inc (2011). 
28. Nada, S.A., Said, M.A., and Rady, M.A. "Numerical investigation and parametric study for thermal and energy management enhancements in data centers' buildings", Applied Thermal Engineering, 98, pp. 110128 (2016).

\section{Biographies}

Mahdi Narimani was born in 1995. He completed his BSc degree in Mechanical Engineering in the branch of Fluid Mechanics and Heat Transfer at Urmia University from 2013 to 2017. He graduated from the Amirkabir University of Technology in 2019 with an
MSc degree in Energy Conversion. His graduate thesis focused on the cooling of the datacenters. Now, he is a member of the Iranian Association of Mechanical Engineers. His research interests include heat, ventilation, and air conditioning studies. Also, he is working on rotating equipment in oil and gas field.

Abbas Abbassi received his $\mathrm{PhD}$ from the University of Birmingham in 1989. He started his career at the Amirkabir University of Technology in the Faculty of Mechanical Engineering. He has published numerous papers and books in the field of energy conversion and HVAC systems design. 